\title{
Mercury films on commercial carbon screen-printed devices for the analysis of heavy metal ions: a critical evaluation
}

\author{
Clara Pérez-Ràfols, Núria Serrano, José Manuel Díaz-Cruz*, Cristina Ariño and Miquel Esteban \\ Departament de Química Analítica, Universitat de Barcelona, Martí i Franquès, 1-11, E-08028 Barcelona, Spain. \\ * e-mail: josemanuel.diaz@ub.edu, corresponding author
}

Received: ((will be filled in by the editorial sttaff))

Accepted: ((will be filled in by the editorial sttaff))

\begin{abstract}
The suitability of mercury films on commercial screen-printed electrodes for the analysis of heavy metal ions is critically tested for the particular case of $\mathrm{Pb}(\mathrm{II})$-ions. Although determination is possible by anodic stripping voltammetry with a reasonable detection limit $\left(8.9 \mu \mathrm{g} \mathrm{L}^{-1}\right)$, important drawbacks are noticed as a consequence of the heterogeneous deposition of mercury on the rough surface of screen-printed devices.
\end{abstract}

Keywords: Mercury film, screen-printed electrodes, anodic stripping voltammetry, $\mathrm{Pb}(\mathrm{II})$-ions.

DOI: 10.1002/elan.((will be filled in by the editorial sttaff))

For many years, mercury electrodes have been essential in Electroanalysis, mainly due to the large cathodic window and the good reproducibility [1-4], but nowadays international safety regulations encourage their replacement by less toxic materials. Solid electrodes coated with bismuth [5-8] and antimony [9-10] can be acceptable substitutes for mercury in many applications, especially in stripping voltammetry of heavy metal ions. The increasing popularity of commercial screen-printed electrodes (SPE) have favoured this strategy, as they provide a cheap, relatively reproducible and disposable support for bismuth or antimony coatings which do not require the tedious cleaning and polishing steps of solid electrodes [11-15]. But there are properties of mercury electrodes still unmatched by alternative materials, such as their strong interactions with thiol peptides of biological interest [16-20]. Thus, it seems reasonable to keep using mercury in those situations where a suitable replacement is not yet available. By other hand, screenprinted electrodes appear to be a more versatile support for mercury films than solid electrodes and, in contrast to mercury drops, they can be easily adapted to flow detection [21]. This is why, taking into account the interesting features shown in previous studies by mercury films deposited on home-made screen-printed devices [22-29], this work focuses on the suitability of such films on commercial carbon screen-printed electrodes (HgSPCE). For this purpose, a typical application of mercury electrodes, i.e. the determination of $\mathrm{Pb}$ (II)-ions, by anodic stripping voltammetry (ASV) is considered as an example of its applicability for the analysis of metal ions.
As a first approach, the screen-printed device was used as a complete cell and the mercury film was deposited according to a method applied to a glassy carbon support [30]. However, this procedure suffered from the fast deterioration of the screen-printed silver acting as reference electrode. This caused a high uncertainty in the measurement of the potentials, leading in extreme cases to the deposition of mercury on the auxiliary electrode. Hence, external reference $(\mathrm{Ag} / \mathrm{AgCl})$ and auxiliary $(\mathrm{Pt})$ electrodes were incorporated and the successive cycles at different deposition potentials were substituted by a single deposition step of $300 \mathrm{~s}$ at $-0.9 \mathrm{~V}$. However, these changes did not improve much the results.

The main reason for the low performance on the screen-printed support of a coating method that yielded good results in glassy carbon electrodes could be attributed to the higher roughness of the screen-printed surface as compared to the mirror-like polished surface of glassy carbon electrodes. This could result in a higher heterogeneity of the mercury coating on screen-printed devices and therefore, a lower reproducibility than conventional mercury films on glassy carbon, as well as the appearance of different signals arising from the interactions of the analyzed metals with the differently covered areas of the film.

Thus, a new methodology for the preparation of the mercury films on screen-printed devices had to be optimized. As SPE cannot be polished, the strategy was focused on improving the homogeneity of the films by making them thicker at increasing deposition times (always at $-0.9 \mathrm{~V})$. The lower time tested $(300 \mathrm{~s})$ did not provide repetitive responses and sometimes double peaks could be observed (Fig. 1). Although better results were 
obtained with $900 \mathrm{~s}$, only by using a deposition time of $1200 \mathrm{~s}$ acceptable results could be achieved (Fig. 1).

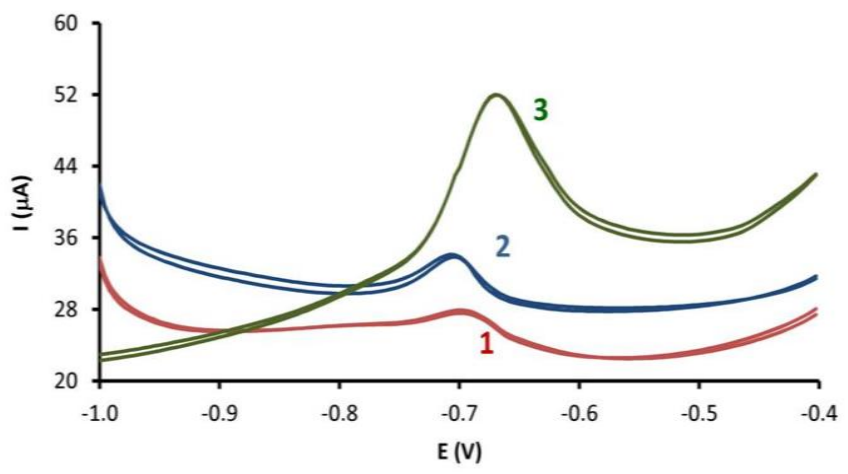

Fig. 1. DPASV signals obtained with different mercury films deposited at $-0.9 \mathrm{~V}$ for $300 \mathrm{~s}$ (1 and 2) and $1200 \mathrm{~s}$ (3) when measuring a solution of $\mathrm{Pb}^{2+} 1 \times 10^{-6} \mathrm{~mol} \mathrm{~L}^{-1}(1$ and 2$)$ or $6 \times 10^{-7}$ mol L $\mathrm{L}^{-1}(3)$. In all cases $\mathrm{Pb}$ was deposited using $\mathrm{E}_{\mathrm{d}}=-1 \mathrm{~V}$ and $\mathrm{t}_{\mathrm{d}}=120 \mathrm{~s}$.

The analysis of the scanning electron microscopy (SEM) images of the mercury films obtained at different deposition times appears to confirm these hypotheses. Fig. 2a shows the rough surface of a bare SPCE and Fig. $2 \mathrm{~b}$ shows essentially the same carbon surface with microscopic mercury drops in the form of bright points, quite separated with each other and not very homogeneously distributed. At $1200 \mathrm{~s}$ the density and the distribution of the drops (in position and size) is quite good (Fig. 2c). Finally, the deposition time of $1500 \mathrm{~s}$ (Fig. 2d) does not improve much the density of drops and start to generate much bigger and smaller drops, which decreases the homogeneity of the film. All that confirms that a time of $1200 \mathrm{~s}$ is optimal for depositing a reliable mercury film at $-0.9 \mathrm{~V}$.

When a HgSPCE prepared according to this optimized procedure is used to carry out DPASV measurements on a lead solution, a peak corresponding to lead reoxidation can be observed at $-0.60 \mathrm{~V}$, but also broad signals at -1.3 and $-0.8 \mathrm{~V}$ (Fig. 3). Different deposition potentials and deposition times were tested (Fig. 3) and values of $-1.0 \mathrm{~V}$ and $120 \mathrm{~s}$, respectively, were finally selected.

By using these experimental conditions, the mercurycoated electrodes could be used for more than 10 times without visible deterioration and with reasonable repeatability (standard deviation around 6\%). This allowed one to obtain well-defined peaks and satisfactory calibration plots for $\mathrm{Pb}$ (II)-ions by using the optimized DPASV procedure on a single HgSPCE, as it is shown in Fig. 4. The limits of detection (LOD $=8.9 \mu \mathrm{g} \mathrm{L}^{-1}$ ) and quantification $\left(\mathrm{LOQ}=29.8 \mu \mathrm{g} \mathrm{L}^{-1}\right)$ were calculated as 3 and 10 times the standard deviation of the intercept divided by the slope of the calibration curve. a)

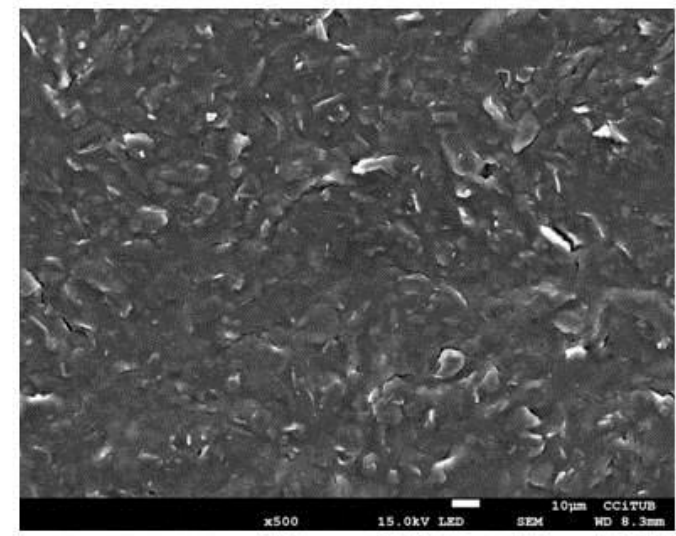

b)

$900 \mathrm{~s}$

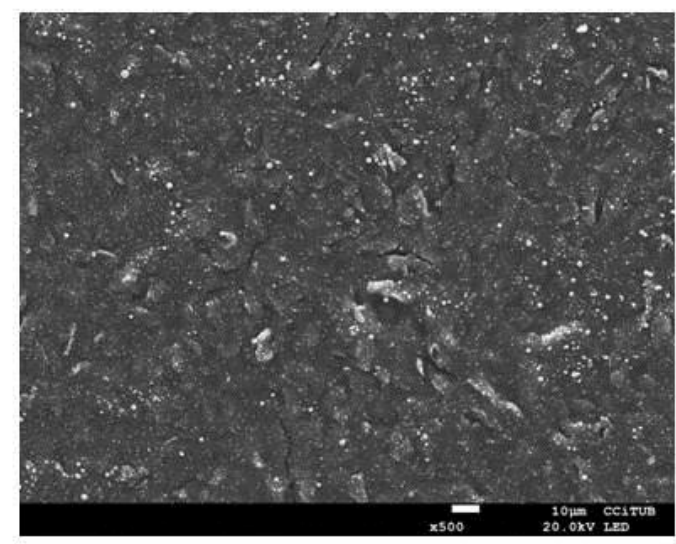

c)

$1200 \mathrm{~s}$

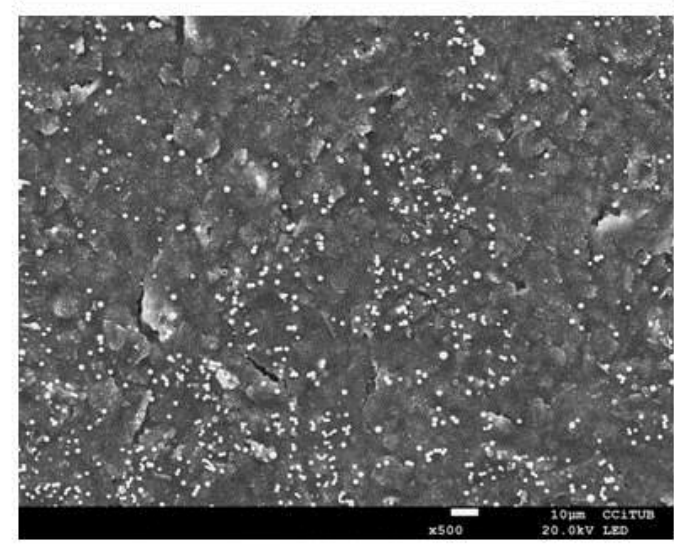

d)

$1500 \mathrm{~s}$

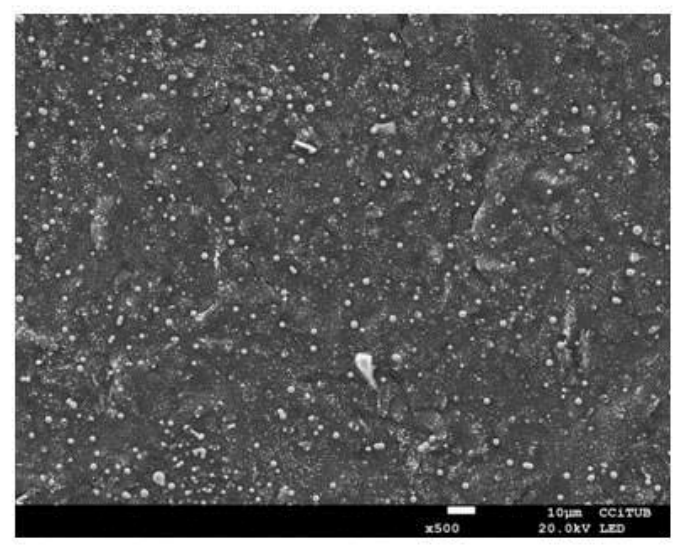

Fig. 2. SEM images (x500 magnification) of mercury films obtained on SPCE devices with different deposition times. 

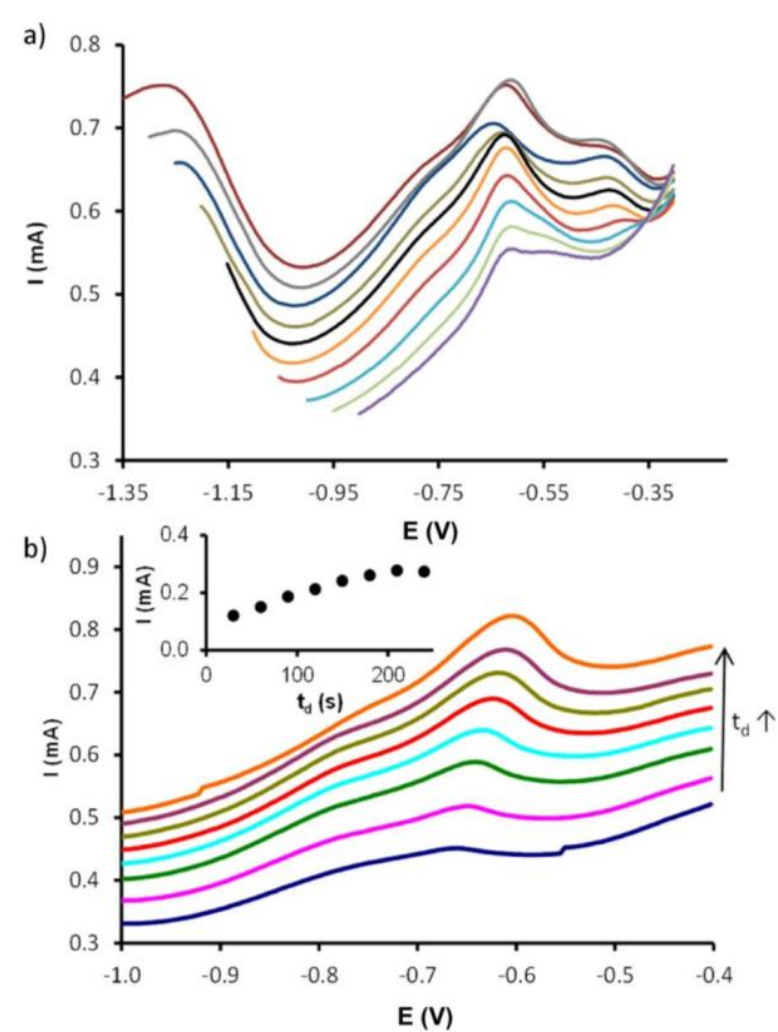

Fig. 3. DPASV signals at different deposition potentials (a) and deposition times $t_{d}$ ranging from 30 to $240 \mathrm{~s} \mathrm{(b)} \mathrm{for} \mathrm{a} \mathrm{solution}$ of $\mathrm{Pb}$ (II) $2 \times 10^{-7} \mathrm{~mol} \mathrm{~L}^{-1}$ (a) and $5 \times 10^{-8} \mathrm{~mol} \mathrm{~L}^{-1}$ (b). The inset shows the dependence of the current on $t_{d}$.

The linearity range was $29.8-229.2 \mu \mathrm{g} \mathrm{L}^{-1}$. Although such figures of merit do not improve the results achieved with bismuth or antimony films, they are of the same order of magnitude $[10,14]$.

As for SWASV measurements (Fig. 4), they produced signals with a higher level of noise and showing a noticeable peak splitting. This may suggest a higher sensitivity of SW scans (much faster than DP ones) to the problems derived from the heterogeneity of the mercury film. Anyway, the calibration line is not bad and the slope is not much lower than that obtained by DPASV.

Thus, in the preliminary test made in this work, mercury coated commercial screen-printed carbon electrodes have shown their ability to determine $\mathrm{Pb}(\mathrm{II})$ ions by ASV in a faster and easier way than using mercury films on conventional glassy carbon electrodes (screen printed devices do not require tedious cleaning or polishing treatments). However, important limitations of screen-printed devices have been also shown, mostly derived from the higher roughness of the material as compared to the mirror-like surface of solid electrodes. This results in a heterogeneous distribution of the microscopic mercury drops on the surface, causing signal splitting and low reproducibility of the measurements. This work has shown that a good strategy to overcome the roughness of the support is increasing the thickness of the mercury film with higher deposition times. Anyway, too high deposition times can increase the film heterogeneity if too large drops are formed. Just to conclude, it seems that mercury films could still play a role in the emerging world of commercial screen-printed electrodes as far as such devices could be produced in a more reproducible way and with a more homogeneous surface. Indeed, previous works have reported mercury deposition on home-made devices without remarkable problems [22-29]. Maybe the commercial screen-printed devices here used (essentially designed for amperometricbiosensing applications) have an excessive roughness that could be improved in the fabrication process. Finally, it should be noted that liquid mercury is much less toxic than, e.g., mercury vapors contained in fluorescent lamps commonly used today, and that many authors still argue that the use of mercury electrodes is safe [31].

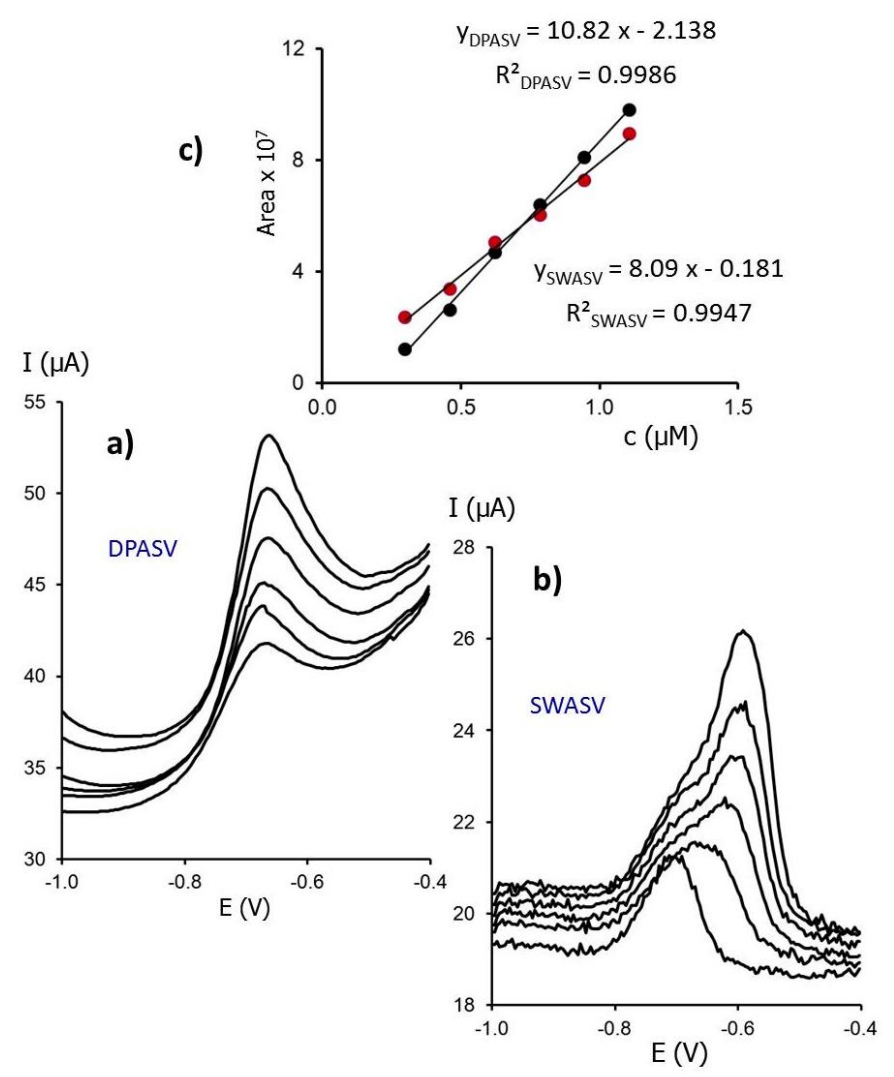

Fig. 4. DPASV (a) and SWASV (b) signals and their corresponding calibration curves (c) for the determination of $\mathrm{Pb}$ (II) with $\mathrm{HgSPCE}$.

\section{Experimental}

Measurements by anodic stripping voltammetry, in both differential pulse (DPASV) and square wave (SWASV) modalities, were performed in a glass cell at $20{ }^{\circ} \mathrm{C}$ by means of a $\mu$ Autolab System Type III (EcoChemie, The 
Netherlands) attached to a Metrohm 663 VA Stand (Metrohm, Switzerland) and a personal computer with GPES 4.9 software (EcoChemie). The reference and the auxiliary electrode were $\mathrm{Ag}|\mathrm{AgCl}| \mathrm{KCl}\left(3 \mathrm{~mol} \mathrm{~L}^{-1}\right)$ and $\mathrm{Pt}$ wire, respectively (Metrohm, Switzerland). The working electrode was prepared from a screen-printed carbon disk electrode of $4 \mathrm{~mm}$ diameter (ref. $110 \mathrm{DS}$ ) provided by DropSens (Spain).

Solutions of $\mathrm{Pb}$ (II) were prepared from $\mathrm{Pb}\left(\mathrm{NO}_{3}\right)_{2} \bullet 4$ $\mathrm{H}_{2} \mathrm{O}$ Merck (Darmstadt, Germany). $\mathrm{KNO}_{3}$ from Panreac was used as supporting electrolyte. $\mathrm{HgCl}_{2}$ and $\mathrm{HCl} 30 \%$ were purchased from Probus (Badalona, Spain) and Merck, respectively. Purified nitrogen (Linde N50) was used for deaeration. Ultrapure water (Mili-Q plus 185 system, Millipore) was used in all experiments.

For the deposition of the mercury film, the SPCE, the reference and the auxiliary electrodes were attached to the stand and immersed into $30 \mathrm{~mL}$ of a solution containing $200 \mathrm{mg} \mathrm{L}^{-1}$ of $\mathrm{HgCl}_{2}$ and $\mathrm{HCl} 0.1 \mathrm{~mol} \mathrm{~L}^{-1}$.

After deaerating the solution for 10 minutes, different deposition potentials were applied for a time ranging from 300 to $1500 \mathrm{~s}$ with solution stirring and $30 \mathrm{~s}$ without stirring. Once the film was deposited all three electrodes were rinsed with water and the mercury solution was replaced by the one to be measured.

In DPASV measurements, the HgSPCE, the reference and the auxiliary electrodes were attached to the stand and immersed into the measure solution, which was deaerated for $10 \mathrm{~min}$. Then a deposition potential of -1.0 $\mathrm{V}$ was applied for $120 \mathrm{~s}$, followed by a rest period of 30 s. Pulse times of $50 \mathrm{~ms}$, step potentials of $4 \mathrm{mV}$ and pulse amplitudes of $50 \mathrm{mV}$ were applied during the stripping step. In SWASV a frequency of $50 \mathrm{~Hz}$ was used.

The surface morphology characterization was carried out by a Scanning Electron Microscope JSM 7100FE from JEOL (Japan).

\section{Acknowledgements ((optional))}

This work is supported by the Ministry of Science and Innovation of Spain (project CTQ2012-32863 and a grant for C. Pérez-Ràfols) and the Generalitat of Catalonia (project 2014SGR269).

\section{References}

[1] A. J. Bard, L. R. Faulkner, Electrochemical methods: fundamentals and applications, $2^{\text {nd }} E d$., Wiley, New York, 2001.

[2] J. Barek, A.G. Fogg, A. Muck, J. Zima, Crit. Rev. Anal. Chem., 2001, 31, 291.

[3] V. Vyskočil, J. Barek, Crit. Rev. Anal. Chem., 2009, 39, 173.

[4] A. Economou, P. R. Fielden, Analyst, 2003,128, 205.
[5] J. Wang, J. Lu, S.B. Hocevar, P.A.M. Farias, B. Ogorevc, Anal. Chem., 2000, 72, 3218.

[6] J. Wang, Electroanalysis, 2005, 17, 1341.

[7] A. Economou, Trends Anal. Chem., 2005, 24, 334.

[8] I. Svancara, C. Prior, S.B. Hocevar, J. Wang, Electroanalysis, 2010, 22, 1405.

[9] S.B. Hocevar, I. Švancara, B. Ogorevc, K. Vytras, Anal. Chem., 2007, 79, 8639.

[10] V. Sosa, C. Barceló, N. Serrano, C. Ariño, J.M. DíazCruz, M. Esteban, Anal. Chim. Acta, 2015, 855, 34.

[11] O. Domínguez-Renedo, M.A. Alonso-Lomillo, M.J. Arcos Martínez, Talanta, 2007, 73, 202.

[12] J.P. Hart, A. Crew, E. Crouch, K.C. Honeychurch, R.M. Pemberton, Anal. Lett. , 2004, 37, 789.

[13] N. Serrano, J.M. Díaz-Cruz, C. Ariño, M. Esteban, Electroanalysis, 2010, 22, 1460.

[14] N. Serrano, A. Alberich, J. M. Díaz-Cruz, C. Ariño, M. Esteban, Trends Anal. Chem., 2013, 46, 15.

[15] M. Maczuga, A. Economou, A. Bobrowski, M. I. Prodromidis, Electrochim. Acta., 2013, 114, 758.

[16] M. Heyrovský, Electroanalysis, 2004, 16, 1067.

[17] M.J. López, C. Ariño, S. Díaz-Cruz , J.M. Díaz-Cruz , R. Tauler, M. Esteban, Environ Sci Technol., 2003, 37, 5609.

[18] G. Scarano, E. Morelli, Electroanalysis, 1998, 10, 39.

[19] N. Serrano, I. Šestáková, J.M. Díaz-Cruz, C. Ariño, J. Electroanal. Chem., 2006, 591, 105.

[20] R. Gusmão, S. Cavanillas, C. Arino, J.M. Díaz-Cruz, M. Esteban, Anal. Chem, 2010, 82, 9006.

[21] S. Cavanillas, N. Serrano, J.M. Díaz-Cruz, C. Ariño, M. Esteban, Electroanalysis, 2014, 26, 581.

[22] I. Palchetti, A. Cagnini, M. Mascini, A.P.F. Turner, Microchimica Acta, 1999, 131, 65.

[23] M. Jasinski, P. Gründler, G.U. Flechsig, J. Wang, Electroanalysis, 2001, 13, 34.

[24] K.C. Honeychurch, J.P. Hart, Trends Anal. Chem., 2003, $22,456$.

[25] R.O. Kadara, J.D. Newman, J. I.E. Tothill, Anal. Chim. Acta, 2003, 493,95.

[26] I. Palchetti, S. Laschi, M. Mascini, Anal. Chim. Acta, 2005, 530, 61 .

[27] O. Domínguez-Renedo, M. Calvo, M.J. Arcos-Martínez, Sensors, 2008, 8, 4201.

[28] O. Domínguez-Renedo, M.J. Gómez González, M.J. Arcos-Martínez, Sensors, 2009, 9, 219.

[29] W. Song, L. Zhang, L. Shi, D.W. Li, Y. Li, Y.T. Long, Microchim. Acta, 2010, 169, 321.

[30] N. Serrano, J.M. Díaz-Cruz, C. Ariño, M. Esteban, J. Electroanal. Chem., 2003, 560,105.

[31] J. Barek, J. Fischer, T. Navratil, K. Peckova, B. Yosypchuk, J. Zima, Electroanalysis, 2007, 19, 2003. 